\title{
RESSENTIMENTO E VINGANÇA: CONSERVAÇÃO E DESAGREGAÇÃo DO ESPAÇO POLÍTICO EM ARENDT
}

\author{
Ricardo Gião Bortolotti ${ }^{1}$ \\ Universidade Estadual Paulista Júlio de Mesquita Filho (UNESP) \\ http://orcid.org/0000-0001-9759-3719 \\ E-mail: bortho@uol.com.br
}

\begin{abstract}
RESUMO:
O espaço público é palco para os mais variados conflitos, resultando, em certos casos, em violência. Entretanto, é nesse espaço que os homens experimentam a liberdade, expressando-se frente à pluralidade de opiniões. Por ser um espaço para a livre expressão, nem sempre nossas ações e opiniões são recebidas sem contrariedade, despertando sentimentos rancorosos. Seguindo o pensamento de Arendt, o espaço público é a arena em que todos devem se manifestar espontaneamente, evidenciando-se a partir de sua singularidade diante da pluralidade que caracteriza a comunidade. Por ser um espaço de manifestação do indivíduo, pautado pela liberdade e pluralidade, a ação é irreversível e imprevisível, possibilitando um ciclo de mal-entendidos e violência. Por conseguinte, não há como impedir que emoções conflitantes sejam alimentadas do prejuízo originado da ação política. Segundo Arendt, ressentimentos são estados emocionais peculiares ao ser humano, facilitando o entendimento comum e a convivência. Assim, o ressentimento pode conduzir a atos contra a injustiça, com a punição e o perdão, possibilitando um novo começo. Contudo, há atos que não se coadunam com o perdão, como os crimes perpetrados pelo nazismo, cuja relação estabelecida entre os homens não era humana. Diante do absurdo da situação, sobre a qual não há como julgar, o perdão não tem lugar, fechando as portas para um novo começo. Enfim, este texto pretende explorar o papel do ressentimento enquanto fator que possibilita a sobrevivência do espaço público, mas que também pode conduzir à sua destruição.
\end{abstract}

PalaVRaS-CHAVE: Espaço público; Hannah Arendt; Política; Perdão; Promessa; Ressentimento.

\section{RESENTMENT AND REVENGE: CONSERVATION AND BREAKDOWN OF THE POLITICAL SPACE IN ARENDT}

\begin{abstract}
:
The public space is the stage for the most varied conflicts, resulting, in certain cases, in violence. However, it is in this space that men experience freedom, expressing themselves in front of plurality of opinions. As it is a space for free expression, our actions and opinions are not always received without contradiction, arousing resentful feelings. Following Arendt's thinking, the public space is the arena in which everyone should manifest themselves spontaneously, showing themselves from their uniqueness before the plurality that characterizes the community. As it is a space for the expression of the individual, guided by freedom and plurality, the individual's action is irreversible and unpredictable, enabling a cycle of misunderstandings and violence. Consequently, there is no way to prevent conflicting emotions from being fed by the damage originated from political action. According to Arendt, resentments are emotional states peculiar to human beings, facilitating common understanding and coexistence. Thus, resentment can lead to acts against injustice, with punishment and forgiveness, enabling a new beginning. However, there are acts that are not in keeping with forgiveness, such as the crimes perpetrated by Nazism, whose relationship established among men was not human. In the face of the absurdity of the situation, on which there is no way to judge, forgiveness has no place, closing the doors to a new beginning. Anyway, this text intends to explore the role of resentment as a factor that enables the survival of public space, but that can also lead to its destruction.
\end{abstract}

KEYWORDS: Publicspace; Hannah Arendt; Politics; Forgiveness; Promise; Resentment.

\footnotetext{
${ }^{1}$ Doutor pela Pontifícia Universidade Católica de São Paulo (PUC/SP), São Paulo - SP, Brasil. Professor da Universidade Estadual Paulista Júlio de Mesquita Filho (UNESP), Assis - SP, Brasil.
}

BORTOLOTTI, Ricardo Gião. Ressentimento e vingança: conservação e desagregação do espaço político em Arendt. Griot : Revista de Filosofia, Amargosa - BA, v.20, n.2, p.360-379, junho, 2020. 


\section{Introdução}

A relação entre os indivíduos de uma comunidade não resulta em contatos tranquilos, mas produz emoções, que em muitos casos resvalam para o ódio. A inveja, o ciúme, o desprezo, o prejuízo nos negócios, etc. são elementos suficientes para ensejar conflitos. A convivência entre os homens parece, de fato, corresponder à insocial sociabilidade kantiana, compreendendo no íntimo de cada um o desejo contrário a aproximações e contatos. Com efeito, a realidade das comunidades mantém-se a partir das ações de seus cidadãos, as quais provocam uma rede de opiniões, suscitando crenças de diversos matizes. Um espaço assim estabelecido é palco da liberdade, cujo movimento político expressa a pluralidade de opiniões, possibilitando a atividade sadia de uma política autêntica. A sobrevivência desse espaço somente é possível a partir da comunicação entre os seus membros, ação que dispensa a violência, cujo efeito é pôr fim às vozes. No entanto, a ação espontânea nem sempre condiz com uma boa reação do outro, uma vez que a pluralidade pressupõe a manifestação de nossas diferenças (JACOBITTI, 1991). Seria possível um espaço vivo sem acarretar choques de opiniões?

A violência entre os membros de uma comunidade pode envolver punição e perdão, mecanismos próprios da justiça e que funcionam a fim de lhes garantir a sobrevivência. As ações políticas, ao interferirem na vida dos cidadãos, também geram atitudes rancorosas, e que devem ser amenizadas pelo arrependimento e perdão. Para Arendt, pensadora central de nossa discussão, a violência destruiria o espaço público, uma vez que promoveria um ciclo de reações, da mesma forma, violentas. Na verdade, para a autora, as ações efetuadas pela comunidade são irreversíveis e imprevisíveis, impedindo o retorno do fato agravante, fator que acarreta a repressão de emoções rancorosas. Diante disso, o que fazer, a não ser proceder ao que é humano, ao que estaria ao alcance da justiça, sem contar com a destruição do outro?

Este trabalho procura discutir o papel do ressentimento na organização do espaço público a partir, especialmente, do pensamento de Hannah Arendt. Antes, porém, de adentrarmos em seu pensamento, apresentaremos algumas definições dessa emoção com o intuito de facilitar o entendimento da posição da autora.

$O$ ressentimento, como uma emoção ${ }^{2}$ fundada numa ofensa ou prejuízo que se guarda, pode ser o pilar da criação do novo juntamente com o perdão ou punição. Entretanto, como teremos a oportunidade de ver, esse tipo de emoção somente é possível diante de uma injúria entre "seres humanos", ou seja, não se trata de uma relação na qual o indivíduo é destituído de sua humanidade. Nesse sentido é que podemos observar o ressentimento moral, atribuído a Adam Smith, e que respeita as questões envolvendo indivíduos; por outro lado, também podemos falar em ressentimento como originário de uma emoção sociopolítica; e, por fim, quando o ressentimento resvala para o ódio e a criação de bodes expiatórios, a emoção é atribuída ao chamado "ressentimento ontológico", cujo principal representante é Nietzsche (URE, 2015, p. 599).

Há situações em que o perdão não é possível, como no caso das políticas totalitárias, especialmente o nazismo. Como Arendt mostrou no caso Eichmann, um crime contra a humanidade está isento de perdão, pois a relação humana deixou de ditar regras. A comunicação não existia, mas apenas a ação dirigida a seres humanos transformados em objetos que "habitavam" a fábrica da morte. Diante de situação tão absurda, como perdoar? O nazismo foi

\footnotetext{
2Utilizamos, para o tratamento do ressentimento, ambos os termos "emoção" e "sentimento", sem discriminá-los, uma vez que há variações nos seus usos conforme os autores trabalhados. Ademais, geralmente ocorrem num mesmo contexto, facilmente compreendidos. Esse uso, indiscriminado, no entanto, não cria confusão no entendimento de nosso tema.
} 
um crime contra o "status humano", levando à perda do significado de humanidade (ARENDT, 2012c, pp. 301-302). Como dissemos, a comunicação baseada no pluralismo e na espontaneidade cedeu lugar para o determinismo das leis totalitárias. Destruiu-se, pois, a essência do humano (HUNT, 2015, p. 287). Nesses casos extremos, as emoções humanas não resistem e o mundo perde o sentido. Por outro lado, o ressentimento pode ser visto como uma emoção positiva se possibilitar algum sentido ao mundo em que vivemos, auxiliando-nos na compreensão das razões de certos atos ou emoções, como o egoísmo, a inveja, etc. Podemos, enfim, compreender o ressentimento que alimentou o antissemitismo, mas os crimes direcionados à humanidade fogem completamente das ações humanas que correspondem ao perdão ou à punição.

Por fim, algumas considerações acerca da sequência assumida pelo texto. Discutimos, em primeiro lugar, algumas definições e características do ressentimento, sem, no entanto, adentrarmos nos meandros das teorias enunciadas, mas apenas para esclarecer algumas categorias. Na sequência, exploramos as noções de espaço público e de política, conforme a posição de Arendt, com o intuito de apesentar ao leitor a importância da arena pública para a liberdade, expressa na pluralidade de opiniões. $O$ terceiro tópico procura mostrar como o espaço público pode sobreviver tecido na pluralidade de opiniões, manifestada a partir do senso comum, ou seja, de forma espontânea. Em suma: nossas ações são irreversíveis e imprevisíveis, podendo acarretar um ciclo mecânico de violência, exigindo, pois, o perdão e a punição para romper tal processo. Finalmente, o último tópico procura abordar o imperdoável, quando as características da natureza humana, como as emoções que guiam os homens nos seus embates, são destruídas pela máquina da morte do totalitarismo.

\section{Ressentimentos}

Podemos dizer que a emoção que se denomina "ressentimento" é um re-sentir (MARIN \& QUINTANA, 2015, p. 93), uma emoção que se repete, vivamente, é, como bem afirma Scheler (1927, pp. 12-13):

[...]um retorno a viver a própria emoção: um voltar a sentir, um re-sentir. [...]. Talvez a palavra "rancor" tenha sido a mais apropriada para indicar esse elemento fundamental de significação. $\mathrm{O}$ "rancor" é, de fato, o que retém a raiva, independente da atividade do eu, que atravessa a alma sombriamente e acaba se formando quando sentimentos de ódio ou outras emoções hostis revivem repetidamente; ainda não contém nenhum desígnio hostil em particular, mas nutre com o sangue todos os desígnios possíveis dessa classe.

É uma emoção contida que sobrevive internamente no indivíduo, reavivando a sua memória. Distingue, pois, da pura e simples agressão, como o revide de um bofete na cara. Vejamos como Scheler (1927, pp. 21-22) caracteriza essa reação de impotência, própria dessa emoção:

O sentimento de vingança, inveja, ojeriza, perfídia, a alegria do mal alheio e a maldade, não entram na formação do ressentimento, mas onde não há lugar nem para a vitória moral (na vingança, por exemplo, um perdão verdadeiro), nem para a ação ou respectivamente -para a expressão adequada de emoção em manifestações externas; por exemplo: insultos, movimentos de punho, etc; e se não ocorrem, é porque uma consciência, ainda mais incriminada da própria impotência, restringe tal ação ou expressão. 
O indivíduo reprime o impulso para a ação, possibilitando a instalação do ressentimento. Pode, então, dar lugar a uma personalidade amargurada, a qual arrasta a vida em lamentações.

Essa definição geral da emoção contida, denominada "ressentimento", importante, de certa forma, para a manutenção da comunidade, uma vez que gerencia nossas paixões antissociais, possibilita, inclusive, a jurisprudência (SCHWARZE\& SCOTT, 2015; MARIN \& QUINTANA, 2015). A reação imediata a um ato de injúria pode conduzir à punição ou ao perdão, livrando os indivíduos de um ciclo de violência indeterminado. Assim, como uma emoção humana, o ressentimento dá o tom do desenvolvimento da civilização.

Segundo Ure (2015, p. 599), essa emoção pode ser concebida de três maneiras diferentes. Assim o autor se refere ao desenvolvimento de seu artigo:

Sugere primeiro que os defensores contemporâneos do ressentimento moral demonstrem plausivelmente que essa emoção é um dos pilares da justiça. Segundo, argumenta que, se aceitarmos uma noção mais ampla de responsabilidade coletiva, também poderemos defender o ressentimento sociopolítico como uma emoção importante para identificar e abordar injustiças coletivas e sistemáticas. No entanto, o artigo também sustenta que o ressentimento sociopolítico tem o potencial de desencadear ou galvanizar o ressentimento ontológico.

A fim de diferenciar a emoção recorrente, mas que pode servir para a estrutura da comunidade, regrando a vida dos indivíduos no âmbito das paixões humanas, alguns autores utilizam a palavra inglesa "resentment", enquanto o termo francês "ressentiment"3 é utilizado para caracterizar o ressentimento ontológico, atribuído a Nietzsche, e que possui uma conotação patológica, compreendida numa acepção biológica (PASCHOAL, 2008; MACLACHLAN, $2010)^{4}$. Pela primeira definição, podemos entender como a coletividade é mantida, perdoando e punindo; pela segunda, questões envolvendo o antissemitismo, com a orientação totalmente racista, centrada em explicações de ordem biológica. Nesse aspecto, veremos, na violência envolvida, o humano sai de cena. As emoções humanas estudadas pelos clássicos da filosofia, o egoísmo, a inveja, a raiva, o ciúme, etc., deixam de valer como elementos de compreensão do relacionamento entre os pares. Com efeito, a preocupação maior para uma comunidade é não resvalar para o ressentimento ontológico, invertendo os valores e buscando um bode expiatório para seus próprios sentimentos, canalizando o ódio. Por outro lado, o ressentimento garante a ordem democrática, buscando-se, a partir dele, uma justificação para a injúria sofrida pela vítima, restaurando o equilíbrio necessário para o convívio democrático. Na verdade, o ressentimento "constitui um marcador normativo de violações injustas e uma demanda para a restauração de igual respeito." É, pois, "um guardião emocional das normas democráticas fundamentais." (URE, 2015, p. 600).

O ressentimento ontológico, por outro lado, não contribui com o espaço democrático, criando condições para "diferentes tipos de política totalitária e perfeccionista", como bem nota Ure (2015, p. 599). A concepção nietzscheana procura mostrar que o ressentimento sociopolítico é um signo de degeneração, e que pode "se transformar em uma inveja radical e em um profundo ódio à existência que identifica a virtude com a vitimização.” (URE, 2015, p. 599).

\footnotetext{
${ }^{3}$ Paschoal (2008, p. 13) esclarece-nos sobre o termo francês ressentiment, utilizado por Nietzsche. Conforme o autor, no século XIX não havia uma palavra em alemão para expressar esse tipo de emoção. Sobre essa dificuldade da tradução do alemão, confira Scheler (1927, p. 12).

${ }^{4}$ Uma exposição esclarecedora acerca do tema pode ser encontrada em, ao menos, dois trabalhos de Giacoia (2001 e 2013).
} 
Sem adentrarmos na complexidade dessa noção para Nietzsche, vejamos como Ure a define a partir de sua leitura da Genealogia da Moral5:

Ressentimento, ele argumenta, é um sintoma de distúrbio fisiológico. Sua origem é um sofrimento constante e inextinguível, derivado de uma incapacidade fisiológica de "incorporar" suavemente as experiências em um projeto contínuo de auto expansão ou esquecer as experiências que se mostram inassimiláveis ou inúteis. Nietzsche define força e fraqueza em termos dessa capacidade de incorporação. Ele identifica tipos fortes e nobres com a capacidade fisiológica de incorporar experiências ao florescimento pessoal. (URE, 2015, p. 602)

E, acrescenta:

Ele afirma que essa degeneração fisiológica - a incapacidade de incorporar ou esquecer a experiência - deu origem a uma variedade de métodos de alívio. Nossa, assim chamada, cultura superior, filosofia, religião e moralidade é, em grande parte, um registro de tais tentativas de trazer alívio aos doentes. (URE, 2015, p. 602) ${ }^{6}$.

E mesmo as mudanças na esfera política ou o reconhecimento mútuo não conduzem à cura dessa emoção. A razão para a carência do esquecimento está justamente no fato de o ressentimento não ser concebido como a falta de reconhecimento social, "mas como um sintoma de uma fraqueza ou degeneração incurável e biológica." (URE, 2015, p.603). Essa concepção, segundo a interpretação de Ure (2015), teria um impacto direto no desenvolvimento das espécies superiores, impedindo-as de se realizar. Ainda, com Ure:

O resentment não implica inveja, mas o ressentiment é alimentado por ela. $\mathrm{O}$ ressentiment simplesmente exige que invejemos a boa sorte deles, não que eles nos prejudiquem de maneira específica ou através de qualquer ação específica. Ou para colocar de outra forma, Nietzsche alega que os degenerados fisiologicamente experimentam a boa sorte de um dano profundo. Os indivíduos do ressentiment não necessitam cometer qualquer dano especificamente direcionado aos degenerados; basta que sejam simplesmente cometidos a si mesmos. (URE, 2015, p. 604)

A comparação dos "escravos" com os nobres também resulta em ressentimento (ressentiment), uma vez que os nobres aparecem como bons, belos e poderosos, enquanto o outro experimenta a impotência (URE, 2015, p. 604). Em consequência, a impotência resulta na transformação de valores, ou seja, o bom, belo e poderoso, passa a ser valorado negativamente, como mau, feio e débil. Com efeito, a partir desses valores, criam-se os novos, o que dá origem à "moral dos escravos" (BRUSOTTI, 2000, p. 12). E essa moralidade, fruto do ressentiment, passa a ter seu desdobramento "... direcionado para o que ele considerava condições naturais de existência: guerra, violência..." (URE, 2015, p. 606). Na realidade, a revolta dos escravos poderia ser classificada como uma espécie de "ressentimento sociopolítico" frente ao

\footnotetext{
${ }^{5}$ A genealogia está estruturada a partir de três ensaios, os quais visam a pesquisa levada a termo por um psicólogo sobre a reavaliação de todos os valores: "A primeira pesquisa é dedicada a investigar o nascimento do cristianismo a partir do 'espírito do ressentiment'; a segunda desenvolve uma 'psicologia da consciência', onde 'consciência' se refere não à voz de Deus no homem, mas ao instinto de crueldade que foi interiorizado depois de ela ser suprimida; a terceira e última pesquisa examina o significado dos ideais ascéticos e, particularmente, indaga como o ideal do 'sacerdote' dá origem a seu grande poder sobre a humanidade." (ANSELL-PEARSON, 1997, p. 142).

${ }^{6} \mathrm{Um}$ excelente trabalho sobre Nietzsche e o desenvolvimento das forças ativa e reativa, definidas segundo a tipologia que originam, e que definem e caracterizam o ressentimento e seus desdobramentos, encontra-se em Deleuze (1976).
} 
ressentimento moral, caracterizado por Adam Smith. Entretanto, conforme Ure, ao abordar o ressentimento sociopolítico - a revolta do escravo -como um ressentiment dirigido contra o que é natural à vida, é tomado por Nietzsche como sintoma de degeneração fisiológica, ou seja, ressentimento ontológico (URE, 2015, p. 607)7.

Segundo Ure (2015), Nietzsche não nega a importância do ressentimento para a moral e a vida social, porém é classificado como uma patologia pelo filósofo. É sintoma de degeneração, e que conduz do ressentimento sociopolítico a um ressentimento ontológico, a partir do qual os valores são invertidos, criando, inclusive, condições existenciais para a polaridade rancorosa. Difere, pois, do sentimento despertado em indivíduos, referindo-se às injúrias coletivas, sofridas por grupos e indivíduos de forma sistemática. (URE, 2015, p. 606).

A reponsabilidade moral individual, por sua vez, é considerada por Adam Smith, a quem passamos a comentar.

Para esse pensador iluminista, há certa aproximação entre a humanidade e a natureza, cujo equilíbrio contribui para preservar o senso de justiça. Atentemos, mais uma vez, às palavras de Ure (2015, p. 601):

A teoria do sentimento moral de Smith identifica um ajuste aproximado entre o desenvolvimento moral da humanidade e seus sentimentos naturais. A natureza providencial de Smith visa preservar a humanidade. A natureza, portanto, deu à humanidade os sentimentos adequados para alcançar esse objetivo. A natureza, ao que parece, nos dotou da capacidade de ressentimento que se presta ao desenvolvimento de um senso de justiça. O ressentimento é a causa eficiente que facilita a causa final da natureza ou o fim. Para realizar e sustentar a justiça, argumenta Smith, devemos cultivar, modular e temperar o ressentimento adequadamente. Precisamos aplicar um diapasão ao ressentimento e garantir que ele atinja o tom certo.

Segundo Fassin (2013, p. 252), a emoção do ressentimento na concepção de Smith não é tanto para punir o agente que produziu uma injúria, embora seja uma reação à dor pelo ato realizado. Trocando em miúdos: a retribuição não deve ser violenta. Nas palavras de Smith (1999, p. 119):

[...] propósito mais almejado pelo ressentimento não é tanto fazer que nosso inimigo, por sua vez, também sinta dor, mas fazê-lo saber que a sente por causa de sua conduta passada, fazê-lo arrepender-se dessa conduta e perceber que a pessoa a quem ofendeu não merece ser tratada daquela maneira.

Não deve levar à pura retaliação selvagem, mas é uma emoção que deve ser "domada pela moral", podendo "ser disciplinada enquanto prevalecer um senso de justiça". (FASSIN, 2013, p. 251). Isso posto, o ressentimento, para Smith, não provoca uma reação violenta, mas moderada, que pode conduzir a uma punição justa por parte do agente que produziu a injúria. $O$ ressentimento (ressentiment) nas mãos de Nietzsche, por sua vez, parte de sentimentos reprimidos, cuja reação contra o dominante é legitimada, com base na inveja e na impotência. Nas palavras de Fassin (2013, p. 253):

Com Smith, estamos no reino psicológico e dentro dos limites da moralidade: o objetivo é explicar e justificar interações sociais envolvendo lesões. Com Nietzsche, estamos no

\footnotetext{
7 “A identificação da virtude moral com a fraqueza é o ponto central do conceito de ressentimento de Nietzsche.” (URE, 2015, p. 608).
}

BORTOLOTTI, Ricardo Gião. Ressentimento e vingança: conservação e desagregação do espaço político em Arendt. Griot : Revista de Filosofia, Amargosa - BA, v.20, n.2, p.360-379, junho, 2020. 
domínio genealógico e nos fundamentos da moralidade: o objetivo é interpretar e abalar a obviedade de nossa certeza moral.

O ressentimento sociopolítico, que envolve a responsabilização da geração atual pelos fatos passados, não considera a responsabilidade moral individual (URE, 2015), mas depende da noção de "responsabilidade coletiva", discutida por Arendt (2004), e que compreende a ideia de que indivíduos e grupos podem se responsabilizar pelas ações cometidas pela comunidade política da qual fazem parte, contando, inclusive, com as injustiças passadas. Vejamos, pois, como Arendt caracteriza essa responsabilidade e qual o papel que assume o ressentimento em seu pensamento.

Para a autora, o espaço político, conforme a ideia de liberdade e a incapacidade de prever ou controlar, sem condições de retomar a ação realizada, desfazendo, assim, seus efeitos, é a condição ontológica da política (ARENDT, 2012a). Essa condição, a nosso ver, não elimina o ressentimento, uma vez que as ações realizadas são irreversíveis, contribuindo para alimentar sentimentos rancorosos. Entretanto, veremos que a sobrevivência da esfera política está justamente em desarmar a possibilidade de transformar o espaço público num campo apropriado para insuflar o ódio e impedir a convivência baseada no diálogo, ou seja, num espaço democrático.

As três concepções de ressentimento englobam a concepção de Arendt, ao menos sob alguns pontos de vista. Para a autora, o ressentimento é uma emoção humana, e que contribui para a manutenção da comunidade, do espaço público, enquanto reino das relações humanas e da esfera política. Embora haja também o perigo de resvalar para o ressentimento ontológico, de tipo nietzschiano, e produzir um estado em que não tem mais retorno, como o advento do nazismo. Com efeito, ainda que o ressentimento conduza à criação do novo, com o perdão e a punição do ato, também pode explicar situações extremas e inumanas, como as do caso Eichmann e do totalitarismo. E, nesse caso, não há perdão, mas há, sim, punição. Há também um aspecto importante no caso Eichmann: a punição envolve um indivíduo, e não a coletividade, a qual pode ser responsabilizada, mas não punida, uma vez que não participaram ativamente das atrocidades do regime (ARENDT, 2004, p. 213). Arendt, inclusive, sobre o sentimento de culpa manietado por minorias, como os brancos em vista da questão racial, os alemães em vista dos crimes do nazismo, afirma: "Quando somos todos culpados, ninguém o é" (ARENDT, 2004, p. 214). Para Arendt, é somente num sentido metafórico que dizemos "que sentimos culpa pelos pecados de nossos pais" (ARENDT, 2004, p. 214), se bem que, segundo a autora, o curso dos acontecimentos pode nos fazer pagar por eles.

Ainda, para a Arendt (2004, p. 215), os padrões legais e morais têm algo em comum:

[...] eles se referem à pessoa ou ao que a pessoa fez; se a pessoa está por acaso envolvida num empreendimento comum, como no caso do crime organizado, o que deve ser julgado é ainda essa pessoa, o grau da sua participação, seu papel específico e assim por diante, e não o grupo. $O$ fato de ser membro só desempenha um papel na medida em que torna mais provável o fato de ela ter cometido um crime [...].

Os crimes do nazismo, da máfia ou de outra organização criminosa, como também daqueles cuja justificativa é a de não passarem de meros "dentes na engrenagem" 8 conduzem ao

8 “6... pequena engrenagem” na máquina da Solução Final...”, conforme Arendt (2011, p. 312; 2006, p. 289). 
tribunal uma pessoa, e é ela quem deverá ser julgada (ARENDT, 2004, p. 215)9. Estamos, pois, falando dos tipos descritos de ressentimentos: o sociopolítico e o moral. Ao focarmos a atenção na emoção atribuída à coletividade, o ressentimento - que cobra o ódio ao diferente, resvalandose para culpar grupos, como os negros e os judeus por ações passadas e sentimentos de inveja e egoísmo - pode ser classificado como sendo o sociopolítico. Por outro lado, ao abordarmos a ação individual, como é a de Eichmann, que pertencia a um grupo dentro da sociedade alemã, cada um deve assumir a responsabilidade por esse pertencimento e pelas ideias disseminadas, baseadas no ressentimento ontológico, e deve ser punido a partir do grau de seu pertencimento ao grupo, uma punição direcionada à pessoa. Além disso, se a sociedade alemã deve ser responsabilizada pelas ações cometidas por seus cidadãos, não pode, enfim, ser considerada culpada por essas mesmas ações.

A autora, ao falar da responsabilidade coletiva, está considerando a responsabilidade política. As palavras de Arendt, ao definir a responsabilidade coletiva como o pertencimento a um grupo:

Esse tipo de responsabilidade, em minha opinião, é sempre política, quer apareça na forma mais antiga em que toda uma comunidade assume a responsabilidade por qualquer ato de qualquer de seus membros, quer no caso de uma comunidade ser considerada responsável pelo que foi feito em seu nome. (ARENDT, 2004, p. 216).

A autora cita a questão da responsabilidade pelos atos de nossos pais, além de Napoleão, que dizia se responsabilizar pelos atos da França desde Carlos Magno. Mas, embora assim nos responsabilizássemos, não cabe a nós a culpa pelo passado (ARENDT, 2011, p. 321); com Arendt (2004, p. 217):

Nesse sentido, somos sempre considerados responsáveis pelos pecados de nossos pais, assim como colhemos as recompensas de seus méritos; mas não somos, é claro, culpados de suas malfeitorias, nem moral nem legalmente, nem podemos atribuir os seus atos a nossos méritos.

Além disso, um homem não vive fora de uma comunidade, o que significa que ele também assume responsabilidade política por esse pertencimento. Há, no entanto, os sempátria, refugiados ou párias, gestados no século XX, e que os torna sem responsabilidade política. Essa condição, de alienados, torna-os também à parte da humanidade, o que não deixa de ser um preço considerável a pagar (ARENDT, 2004, p. 217-218).

$\mathrm{O}$ ressentimento está intrinsecamente ligado à questão da responsabilidade moral, uma vez que envolve conflitos originados da coletividade. Entretanto, como observamos, a atribuição de punição não se aplica ao grupo, a não ser que todos, de fato, tenham concretizado o ato injurioso, porém, pode ocorrer que, do grupo, alguns devam mais do que outros, relativizando a participação de cada um (ARENDT, 2004, p.215).

Por fim, a discussão da emoção do ressentimento compreende, como vimos, a questão da manutenção ou destruição do espaço público, com o risco de uma política totalitária. Tal questão toca, pois, à constituição do espaço público e sua caracterização.

\footnotetext{
${ }^{9}$ Segundo Schio (2010, p. 167), a responsabilidade, nesse caso, é individual, "pois cabe a cada um refletir sobre os próprios atos e intenções". A vida política pressupõe essa postura ética perante o mundo, e que diz respeito a cada um. A responsabilidade "será coletiva enquanto preocupação política, por englobar as questões que são relevantes para todo grupo humano (existente ou vindouro)".
} 


\section{O espaço público e suas vicissitudes}

O fato de os seres humanos habitarem o mundo implica algo mais do que, por exemplo, um animal qualquer repartir o mesmo espaço. A razão é simples: seres humanos não se contentam apenas em falar e se comunicar, mas, ao expressarem suas opiniões, possibilitam a discussão, a qual envolve diferentes pontos de vista. $O$ mundo assim formado é baseado na pluralidade. Assim, “... sendo plural, os seres humanos podem se reunir para formar um espaço entre si, e nesse espaço podem observar seu mundo comum sob diferentes pontos de vista e, portanto, falar sobre assuntos comuns." (CANOVAN, 1995, p. 111). Tal peculiaridade é própria dos homens, os quais, por serem plurais, formam um espaço comum.

O espaço público caracteriza-se, pois, por ser o cenário em que a ação e o diálogo são atividades essenciais. A autora utiliza a arena grega antiga como exemplo do que seria o espaço público, marcado pela separação do espaço privado (ARENDT, 2012a). A principal característica da polis era o diálogo, expressão da opinião na ágora, e que dizia respeito aos cidadãos, proprietários e indivíduos livres. Naquele espaço estavam entre iguais, expressando-se com suas particularidades e confrontando-se em discussões. A esfera privada era reservada ao chefe de família, ao proprietário dos bens que lhe pertenciam, como escravos, mulheres e tudo o que compunha a área de sua propriedade. Nesse domínio, o homem não necessita do diálogo, mas sua ação é baseada em seus desejos privados, e o mundo comum passa a ser visto apenas sob um ângulo, sem que se importe com o outro.

Na obra A condição Humana (2012a), Arendt expõe de forma clara como as transformações, com o avanço da civilização e a modernidade, conduziram ao esfacelamento das fronteiras bem marcadas entre a esfera privada e pública. Com efeito, o diálogo e a ação livre, próprios do espaço público, foram substituídos pelas exigências de cunho privativo, tendo o trabalho (labor) alçado à categoria mais importante ${ }^{10}$. $\mathrm{O}$ espaço público cedeu lugar à esfera social e ao domínio das massas. Assim, o consumo parece ditar as regras do mundo moderno. Ora, quando falamos em consumo, estamos apenas nos referindo ao fato de no sistema capitalista a finalidade consistir em seu próprio sustento, baseado na fabricação e no labor. $O$ espaço público, sob essa consideração, deixa de ser o espaço da liberdade, no qual os destinos da cidade estão acima dos desejos do indivíduo. Passa a ser o local das reivindicações sociais de cunho privado.

A atividade política, desenvolvida a partir da ação e da discussão, somente é possível nesse espaço plural, local da liberdade. Com efeito, ao espaço privado caberia apenas a tirania do proprietário, tendo em conta a Antiguidade. Na sociedade moderna, como o social se sobrepõe aos espaços público e privado, as questões que dominam são direcionadas por finalidades singulares, ou seja, não almejam a participação da comunidade para, na verdade, destituir a fala de sua condição singular, lançando-a na rede de opiniões, no embate plural. Tal ação seria apropriada para a constituição de um mundo comum. Assim manifestada, a opinião individual tornar-se-ia matéria do senso comum, colocando-se à mercê da reflexão da comunidade.

A privação da ação e do diálogo corresponde à perda da liberdade, e com ela, o fim do espaço público (ARENDT, 2009a). Nos estados totalitários ideologias ditam as normas à

\footnotetext{
${ }^{10} \mathrm{Em}$ A condição humana (2012a), a autora utiliza três categorias para expor a experiência humana de existir: o trabalho (labor), próprio da vida biológica, consumindo-se no ato de sobreviver; a fabricação (work), responsável pela atividade mais durável, como o mundo artificial que se ergue a nossa volta, e do qual necessitamos para exercer todas as atividades proclamadas pela civilização; e, por fim, a ação, categoria responsável pela atividade política ou motivada pela liberdade.
} 
comunidade, impondo-se a partir da força ${ }^{11}$. A partir da violência, dificilmente a ação, que consiste na aparição do indivíduo no espaço de discussão, teria validade, repercutindo em todos, e mesmo que provoque reações, apenas no mundo interno ela experimentaria a liberdade.

A violência desenfreada destruiria o espaço público, uma vez que acabaria com a pluralidade e, em consequência, com a liberdade. O senso comum se desfaria em prol de indivíduos isolados. Como manter, pois, o espaço político sadio? Como evitar que a ação provoque reações violentas, quando sabemos que, por ser plural, a atividade pública enfrentará opiniões diversas e provocará também reações contrárias? Na verdade, um espaço livre de violência seria irreal (DUARTE, 2009b; ARENDT, 2009b), o que deve ser evitado é a mecanização dessa ação, ou seja, violência que se desdobra em violência. Veremos no próximo tópico que o perdão possibilita a quebra desse ciclo, uma vez que quem perdoa age concretamente (ARENDT, 2012b).

Um ponto é certo: “A liberdade como fato demonstrável e a política coincidem e são relacionadas uma a outra como dois lados da mesma matéria." (ARENDT, 2009a, p. 195). A ação livre é capaz de transcender os motivos e objetivos, abrindo espaço para a imprevisibilidade. A manifestação da opinião insere-se no espaço plural, provocando reações irreversíveis. Ao manifestar uma opinião, o indivíduo aparece no espaço público, interagindo em companhia. E, sem uma finalidade determinante da ação, não tem como prever as reações, as quais podem ser diversas, desde opiniões semelhantes, distintas, mas também algum desagrado (KRISTEVA, 2002, p. 206). O "milagre" do nascimento rompe com os automatismos, originando um novo começo, imprevisível e irreversível (ARENDT, 2009a, p. 219).

A autora afirma que o homem partilha sua existência com o mundo a sua volta ao mesmo tempo que se distingue, sendo plural na medida em que é singular (ARENDT, 2012a, p. 220). Sobre isso, atentemos a um trecho de Arendt (2012a, p. 220):

O discurso e a ação revelam essa distinção única. Por meio deles, os homens podem distinguir a si próprios, ao invés de permanecerem apenas distintos; a ação e os discursos são os modos pelos quais os seres humanos aparecem uns para os outros, certamente não como objetos físicos, mas qua homens.

$O$ discurso e a ação diferenciam os homens dos outros animais, mas também os distinguem entre $\mathbf{s i}^{12}$. Em outros termos, somos iguais por compartilhar o mesmo "mundo", participando do "nós" que constitui o tecido da comunidade, porém somos distintos ao expressarmos nossa opinião diante da arena plural. As diferenças correspondem à opinião apropriada de cada um, conforme o estofo de sua subjetividade. Expondo-se assim, o homem nasce uma segunda vez, mas na esfera pública, para o mundo político ${ }^{13}$, provocando, com a sua posição, reações, algumas favoráveis, outras contrárias. O espaço público é erigido dessa liberdade, sob a qual cada um pode expressar-se segundo sua opinião, sem ser coagido.

A participação e a liberdade são, portanto, pilares da esfera política, sem os quais deixariam de existir. Certamente que o existente deve fornecer sustentação, uma vez que sem o mundo concreto e durável não haveria espaço para a atividade política. Por outro lado, a carência do diálogo é a principal referência para um espaço dominado pela força, pelas ideologias

\footnotetext{
11 Sobre essa e outras noções importantes para o desenvolvimento do pensamento de Arendt, como vigor, poder, autoridade e legitimidade, confira Sobre a violência (ARENDT, 2009b).

${ }^{12} \mathrm{~A}$ ação torna o mundo humano (SCHIO, 2010, p. 168), e o discurso é um tipo de ação, como bem mostra os trabalhos de Honig (1991 e 1993)

13 "ser humano e ser livre são única e mesma coisa. Deus criou o homem para introduzir no mundo a faculdade de começar: a liberdade." (ARENDT, 2009a, p. 216).
} 
totalitárias. Assim sendo, a questão da manutenção desse espaço é de suma importância. Como isso é realizado, diante das controvérsias e do domínio de sentimentos contrários à convivência?

A ação humana é irreversível e imprevisível, perdurando no tempo, o que se revela, no espaço público, fonte de confusão. $O$ fato de os atos persistirem, estendendo-se no tempo, seria, segundo a autora, um fator de orgulho para os homens, caso estes conseguissem suportar "o ônus da irreversibilidade e da imprevisibilidade" (ARENDT, 2012a, p. 291). Ainda, sobre isso, atentemo-nos a um trecho mais longo:

\begin{abstract}
Os homens sempre souberam que aquele que age nunca sabe completamente o que está fazendo; que sempre vem a ser 'culpado' de consequências que jamais pretendeu ou previu; que, por mais desastrosas e imprevistas que sejam as consequências do seu ato, jamais poderá desfazê-lo; que o processo por ele iniciado jamais se consuma inequivocamente em um único ato ou evento, e que seu verdadeiro significado jamais se desvela para o ator, mas somente à mirada respectiva do historiador, que não age. (ARENDT, 2012a, p. 291).
\end{abstract}

A incerteza inerente à participação através da exposição de nossas opiniões não deve afastar o homem de sua interação; pelo contrário, ele deve ousar e expor-se junto à diversidade. As consequências imprevisíveis, no entanto, devem ser superadas a partir do ato de perdoar. Na verdade, sem os atos de prometer e de perdoar, não haveria novo começo, mas sobreviria a confusão, um espaço aberto para a liberação da violência como consequência última das ações. Assim, a promessa, segundo Arendt (2012a, p. 295), "serve para instaurar no futuro, que é por definição um oceano de incertezas, ilhas de segurança sem as quais nem mesmo a continuidade, sem falar na durabilidade de qualquer espécie, seria possível nas relações entre os homens.". $O$ perdão, por sua vez, "serve para desfazer os atos do passado, cujos "pecados' pendem como a espada de Dâmocles sobre cada nova geração..." (ARENDT, 2012a, p. 295). No espaço político, um domínio em que a pluralidade e a liberdade devem prosperar, tais atos do passado não devem ser negligenciados. De fato, os eventos prometidos podem não acontecer da forma prevista, o que pode gerar ressentimentos, mas a possibilidade do arrependimento e do perdão conduz a um novo começo.

A capacidade de perdoar é importante para o homem por romper com a possibilidade de a ação não se esgotar, mas continuar indefinidamente tendo como fonte um único ato. $O$ perdão e a promessa são duas formas de criarem novos espaços de ação, cooperando na manutenção do domínio político. Por via delas, se aceita o erro, cuja fonte está na consequência de nossas ações, imprevisíveis e irreversíveis.

As capacidades de perdoar e de prometer são essencialmente humanas, e segundo Arendt, políticas, exercidas no espaço plural. Como já dissemos, não há garantias de que nossas promessas sejam cumpridas (LA CAZE, 2014, p.209). E, como estamos no terreno das atividades humanas, as reações emocionais permeiam as ações efetuadas no domínio público. Como tivemos a oportunidade de ver, na exposição do primeiro tópico, alimentamos ressentimentos de tipos variados. A questão que se coloca é de qual a melhor forma de lidarmos com essas emoções, sem, no entanto, rompermos com o espaço de discussão. 


\title{
O espaço público e sua manutenção: o perdão e a promessa como formas de anular o efeito da
} fragilidade da ação política

O espaço público constituído a partir da liberdade e, portanto, da espontaneidade de nossas ações, está à mercê das consequências delas advindas. A partir da ação humana, quantos objetivos opostos não serão perseguidos? Afinal, como uma promessa, realizada na esfera política, poderá ser cumprida com plena satisfação? E os desdobramentos imprevisíveis dessa ação, a quantos não afetará, gerando algum tipo de sentimento negativo? Parece que aquele ditado popular "quem sai na chuva é pra se molhar" é válido no contexto da ação política, como bem afirma Arendt, neste trecho de Entre o passado e o futuro (2009a):

\begin{abstract}
A ação humana, projetada em uma rede de relacionamentos onde fins numerosos e antagônicos são perseguidos, quase nunca satisfaz a sua intenção original; nenhum ato pode jamais ser reconhecido por seu executante como seu com a mesma alegre certeza com que uma obra de arte de qualquer espécie será identificada por seu autor. Quem quer que inicie um ato deve saber que apenas iniciou alguma coisa cujo fim ele não pode nunca predizer, ainda que tão-somente por seu próprio feito já alterou todas as coisas e se tornou ainda mais impredizível. (ARENDT, 2009a, p. 120).
\end{abstract}

Não há qualquer garantia de que nossas promessas alcançarão o objetivo. A esfera política não possui outra forma de funcionamento, uma vez que o controle acabaria com a espontaneidade, abrindo espaço para políticas totalitárias ${ }^{14}$. Neste caso, o controle passa a ser absoluto, cujas ações são mecânicas e repetitivas, fundadas inteiramente numa teoria, a qual expõe as condições gerais a serem seguidas. A teoria do contrato social, por exemplo, baseia-se numa ficção, num estado irreal, em que devemos concordar com os termos, e não na espontaneidade definida pela liberdade do espaço plural (ARENDT, 2001, p. 208, 218). Com efeito, para preservar a criatividade, a novidade no espaço público, devemos conviver com esse tipo de fragilidade, o que se traduz por liberdade de agir frente à pluralidade de opiniões. Por essa situação da experiência política é que a promessa reveste-se de importância: cria-se a expectativa de eventos futuros compartilhados no seio da pluralidade, cuja direção pode ser repensada e rediscutida.

A sobrevivência da política autêntica exige o perdão e a promessa, ações discutidas, mais extensamente, em duas obras de Arendt: o perdão é explorado em $A$ condição Humana, enquanto a promessa é discutida na obra Sobre revolução. (LA CAZE, 2014, p. 209). A ação humana não se dá em isolamento, como ocorre, por exemplo, com a fabricação de um produto qualquer. Com Arendt (2012, p. 235):

Estar isolado é estar privado da capacidade de agir. A ação e o discurso necessitam tanto da presença circunvizinha da natureza, da qual obtém seu material, e de um mundo onde coloca o produto acabado. A fabricação é circundada pelo mundo e está em permanente contato com ele; a ação e o discurso são circundados pela teia de atos e palavras de outros homens, e estão em permanente contato com ela.

\footnotetext{
${ }_{14}$ Em Sobre a Revolução (2001, p. 171), Arendt esclarece que a promessa é baseada na pluralidade, ou seja, não é realizada no isolamento; a teoria social do contrato, por sua vez, é baseada num consenso fictício, o qual exigiria como condição o acordo entre os termos. Certamente que a teoria do contrato ganha em isolamento. Na leitura de La Caze (2014, p. 217), a promessa corresponde à experiência da pluralidade e da comunidade, mas sob o contrato, o poder é sacrificado em nome do "poder de estado".
} 
Em A condição humana (ARENDT, 2012a), Arendt expõe algumas das razões de o perdão e a promessa serem estabelecidos: uma delas é, como já dissemos, a fragilidade da natalidade; a outra encontra-se na irreversibilidade da ação, a qual, ação, não pode ser desfeita quando finalizada. Quanto à imprevisibilidade, não temos o controle sobre o nosso interlocutor, ou seja, não sabemos qual seria a sua reação. Por fim, a falta de limite de nossas ações, provocando, quando realizadas, uma reação em cadeia, bem sintetizada pela autora na frase: "todo processo é causa de novos processos". (ARENDT, 2012a, p. 238).

Ora, essas três razões são suficientes para que reações violentas possam surgir, mas que também possam gerar ressentimentos, ações suspensas e que estimulam a imaginação para atos violentos. Como a existência humana é tecida pelas ações realizadas pela comunidade no embate da pluralidade de opiniões, nas quais cruzam diferenças e promessas, que, em muitos casos, podem produzir insatisfações e prejuízos, a saída pode estar na reação imediata, na suspensão da ação ou no perdão. A reação imediata, por exemplo, de vingança, está excluída da noção de ressentimento, que se define pela inibição da ação, lembrada e reconstruída pela imaginação, é a "vingança imaginária", descrita por Nietzsche (2004, p. 29apud GIACOIA, 2001, p. 82). Por fim, o perdão e o castigo/punição afastam as reações nefastas, conduzindo a um novo começo.

O remédio para as ações no espaço público, portanto, está na faculdade de prometer e de perdoar, como bem afirma Arendt (2012a, p. 295):

\begin{abstract}
A redenção possível para a vicissitude da irreversibilidade - da incapacidade de desfazer o que se fez, embora não se soubesse nem se pudesse saber o que se fazia - é a faculdade de perdoar. O remédio para a imprevisibilidade, para a caótica incerteza do futuro, está contido na faculdade de prometer e cumprir promessas. As duas formam um par, pois a primeira delas, a de perdoar, serve para desfazer os atos do passado, cujos "pecados" pendem como espada de Dâmocles sobre cada nova geração; e a segunda, o obrigar-se através de promessas, serve para instaurar o futuro, que é por definição um oceano de incertezas, ilhas de segurança sem as quais nem mesmo a continuidade, sem falar na durabilidade de qualquer espécie, seria possível nas relações entre os homens.
\end{abstract}

Essas duas ações garantem a condição para a existência do espaço necessário para a livre manifestação, uma vez que não só teriam a capacidade de neutralizar a possibilidade da violência, mas também a de criar espaço para o novo, para um novo começo na esfera política, como podemos notar na abordagem de Arendt sobre a categoria da ação em relação às categorias do trabalho (labor) e da fabricação (work), próprias do animal laborans - condicionado ao domínio biológico -o homo faber - responsável pelo mundo a nossa volta, pois garante a permanência material -, e, por fim, o político (ação), cuja atividade principal é o diálogo (ARENDT, 2012a). Com a natalidade, as ações geram novos embates, cujas consequências recriam o ciclo de reações novamente. A promessa seria a garantia do acordo na presença de outros, assegurando a identidade daquele que prometeu e o seu cumprimento (ARENDT, 2012a, p. 296). E, se não fôssemos perdoados, ficaríamos limitados a um único ato, sofrendo para sempre as suas consequências (ARENDT, 2012a, p. 295). Percebe-se que, sem essas duas faculdades, a vingança ou a reação imediata resultariam numa ação determinística, sem um término, o que acarretaria o fim da humanidade. O ressentimento, como uma reação inibida em sua finalidade, por sua vez, expressar-se-ia nas várias formas de justiça, incluindo a punição. Com o perdão e a promessa esse sentimento negativo poderia ser neutralizado.

Algumas ações, no entanto, são imperdoáveis, de modo que o perdão "não se aplica ao caso extremo do crime e do mal voluntário" (ARENDT, 2012a, p. 299). A ofensa, segundo a autora, é uma ocorrência cotidiana, e que envolve múltiplas relações, necessitando do perdão

BORTOLOTTI, Ricardo Gião. Ressentimento e vingança: conservação e desagregação do espaço político em Arendt. Griot : Revista de Filosofia, Amargosa - BA, v.20, n.2, p.360-379, junho, 2020. 
para a liberação da ação e a continuidade da vida (ARENDT, 2012a, p. 300). Por conseguinte, a forma mais relevante do perdão é mais pessoal do que política, conforme ela mostra com a punição, ou seja, o castigo recai em quem pratica a ação, evitando que emoções violentas sejam liberadas ou represadas enquanto formas reativas.

O "mal radical", definido por Kant e utilizado por Arendt no seu trabalho sobre o totalitarismo, constitui uma realidade além da punição e do perdão, uma vez que envolve dificuldades para sua compreensão, transcendendo o reino dos negócios humanos. Nas palavras de Arendt (2012a, p. 301):

Sabemos apenas que não podemos punir nem perdoar esse tipo de ofensas e que, portanto, elas transcendem o domínio dos assuntos humanos e as potencialidades do poder humano, os quais destroem radicalmente sempre que surgem. Em tais casos, em que o próprio ato nos despoja de todo o poder, só resta realmente repetir com Jesus: 'Seria melhor para ele que se lhe atasse ao pescoço uma pedra de moinho e que fosse precipitado ao mar'.

O mal radical priva o indivíduo de sua cidadania, jogando-o para o limbo, sem liberdade e sem escolha ele passa para a categoria de indivíduos supérfluos. Em As Origens do Totalitarismo (2012c), a autora descreve como a busca da transformação da natureza humana pelas fábricas da morte embruteciam os homens:

[...] os campos de concentração constituem os laboratórios onde as mudanças na natureza humana são testadas, e, portanto, a infâmia não atinge apenas os presos e aqueles que administram segundo critérios estritamente 'científicos'; atinge a todos os homens. [...].Os que manipulam esse sistema acreditam na própria superfluidade tanto quanto na de todos os outros, e os assassinos totalitários são os mais perigosos porque não se importavam se estão vivos ou mortos, se jamais viveram ou se nunca nasceram. (ARENDT, 2012c, p. 510)

Esse tipo de mal escapa da compreensão, pois não pertence às categorias comuns, como a ganância, ódio, ressentimento, egoísmo, sadismo, crueldade, etc. Podemos entender um crime comum, a partir da exposição de suas motivações, as quais se classificam no interior do universo humano, amplamente discutido pelos pensadores ao longo da história. A própria literatura encontra em motivações um veio rico para o seu progresso. No caso do mal radical, a desumanização atinge a todos os envolvidos, algozes e vítimas, sem restrição. Essa política embrutecedora, própria do nazismo, e que atingiu toda a Europa, abriu um abismo no contínuo da tradição (ARENDT, 2009a).

Mas, se o mal radical transforma os homens em seres supérfluos, o "mal banal", definido no julgamento de Eichmann por Arendt, caracteriza aquele que não pensa, que, tal como um robô, cumpre ordens sem questionar. Para a autora, a punição deve proceder, uma vez que o perdão, para tal crime desumano, está descartado. Ademais, qual deveria ser o grau de punição? Para a gravidade do crime, cujo extremismo torna-o incomensurável (ARENDT, 2011apud LA CAZE, 2014, p. 213), Eichmann deve ser condenado à morte.

Um aspecto importante dessa questão é a quem o perdão se aplica. Para Arendt, ele se dirige ao "quem" (who) (ARENDT, 2012a, p. 301). Com efeito, não é o crime que é perdoado, mas a pessoa (ARENDT 2004, p. 160; LA CAZE, 2014, p. 213; KRISTEVA, 2002, p. 208), que pensa e se comunica através do diálogo. $O$ perdão somente tem sentido em relação ao outro (KRISTEVA, 2002, p.212), envolvendo a singularidade e a diferença, expressas na fala, na 
comunicação com o outro. É, pois, um ato performativo, uma vez que envolve a enunciação de uma opinião, a comunicação com o outro, transformando, dessa forma, o cenário existente (HONIG, 1991; ARENDT, 2012a).

Segundo Hunt (2015), o perdão tem o poder de mudar a realidade, possibilitando um novo começo, já que uma ação foi efetivada. Assim, livrando-se da exigência de vingança, o indivíduo estará livre para a ação espontânea novamente (HUNT, 2015, p. 284). A possiblidade de vingança impede a emergência do novo, reproduzindo o fato que gerou rancor. Com efeito, um ato vingativo conduz a uma comunidade destituída da atividade humana por excelência, que é o diálogo plural. A violência tolhe o diálogo, impondo um modo de convivência pelo único meio possível: a força. Por isso, Arendt (2012a, p. 300apud HUNT, 2015, p. 284) afirma que "[...] perdão é a única reação que não re-age (re-act) apenas, mas age de novo e inesperadamente, sem ser condicionada pelo ato que a provocou e de cujas consequências liberta, por conseguinte, tanto o que perdoa quanto o que é perdoado". Por conseguinte, com o perdão, o autor se vê liberto da possibilidade de novos atos injuriosos, podendo agir novamente de forma espontânea (HUNT, 2015, p. 284).

Para Arendt, segundo a leitura de Hunt (2015), o perdão não se resume a um ato de compaixão, mas ela "entende o perdão como uma cura para a irreversibilidade da ação, não a violência". (HUNT, 2015, p. 284). No entanto, como já apontamos, há casos extremos em que não se aplicam nem o perdão nem a punição, e que, a nosso ver, inserem-se nos casos em que o ressentimento perpassa toda coletividade. Nesse caso, como vimos, envolve a responsabilidade coletiva, mas envolve também a responsabilidade individual enquanto participação do grupo. Nos excessos, justificado pelo ressentimento ontológico, sobrevém o absurdo das ações, e já não se pode contar com a sobrevivência do espaço público.

\section{Considerações finais: a possibilidade do novo, o absurdo e o limite do perdão}

O espaço público e plural, como vimos, está assentado em forças agônicas, mas necessárias para a saudável vivência política. Segundo Hunt, o ressentimento contra a injustiça "somente é possível dentro de uma comunidade engajada em relações moral e de reconhecimento" (HUNT, 2015, p. 283). Vimos como a ação política define um horizonte de expectativas incontroláveis, pois nossas ações são espontâneas, enfrentando resistências e produzindo sentimentos contraditórios. A possiblidade de emoções violentas deve ser neutralizada, mas não inteiramente, uma vez que se pressupuséssemos um ambiente sem qualquer tipo de violência, estaríamos criando expectativas ilusórias, um estado fictício. Por conseguinte, a repressão pode, de fato, alimentar emoções de ódio inibidas em sua finalidade, mas que, de certa forma, podem contribuir para a sobrevivência do pluralismo ${ }^{15}$.

Para Arendt, na interpretação de Hunt, o perdão é um estado criativo, mas a busca da vingança, não. Entretanto, nem sempre o perdão é possível, pois o espaço para o ressentimento pode ser completamente aniquilado, frente, por exemplo, à injúria massiva. (HUNT, 2015, p. 283). Com efeito, a vivência baseada na vingança, ou seja, quando o ressentimento (resentment) deixa de ser o chão para as relações no espaço público, advém o sentimento de vingança, de ódio e inveja. Nesse estado irrompem sentimentos que correspondem ao ressentimento denominado

\footnotetext{
15 Nas palavras de Arendt (2012a, p. 300):

"Somente mediante essa mútua e constante desobrigação do que fazem os homens podem ser agentes livres; somente com a constante disposição para mudar de ideia e recomeçar pode-se confiar a eles um poder tão grande quanto o de começar algo novo."
} 
de ontológico (ontological ressentiment), discutido por Nietzsche (URE, 2015), e que facilita o surgimento de diversas formas de totalitarismo (URE, 2015).

A vingança, como já foi dito, potencializa o ciclo de violência, uma vez que, esta última, não teria fim (ARENDT, 2012a). A punição, com efeito, teria o poder de colocar fim ao ciclo, funcionando como o perdão. Para Arendt, punição e perdão são alternativas para a mesma finalidade (HUNT, 2015, p. 285). Citamos, por fim, um trecho de Kristeva (2002, p. 208): "O castigo, em seu espírito, diferente da vingança, não contradiz a lógica suspensiva do perdão: como perdão, o castigo põe termo a uma coisa que, sem isso, poderia retornar interminavelmente".

Mas se há injúrias e atos violentos passíveis de perdão e punição, contribuindo para a continuação saudável da convivência coletiva, há, no entanto, ações que escapam de qualquer classificação, como as perpetradas pelo totalitarismo que assolou especialmente a Europa no século XX. Os crimes do nazismo estão, para a autora, fora da alçada do perdão, uma vez que escapam de uma explicação plausível, abrindo um grande abismo na tradição, diferindo de todos os crimes de guerra. O tratamento desumano dispensado aos judeus não corresponde às formas utilizadas no convívio entre os homens e para os homens. Daí, Arendt afirmar que "os homens são incapazes de perdoar o que não podem punir, e que são incapazes de punir o que é imperdoável" (ARENDT, 2012a, p. 301). Antecipando sua análise dos crimes de Eichmann contra a humanidade, Arendt anuncia em A Condição Humana (2012a) os limites não apenas da lei, mas do perdão: quando um crime se torna incomensurável perante a punição, também é incomensurável perante o perdão. O que é impune é imperdoável.

O caráter determinístico que move a ação é a característica principal desse tipo de crime, e que o torna imperdoável. A ação não é imediata e movida por alguma injúria, mas é motivada por uma ideologia que trata o outro como destituído de humanidade. Tal relação não satisfaz a condição humana de ambos os lados, pois ao tratar o outro como mero objeto, o nazista também se desumaniza, uma vez que sua relação não corresponde ao essencial entre os homens, que é a comunicação, como bem afirma Arendt em Homens em Tempos Sombrios (1987, p. 31):

[...] o mundo não é humano simplesmente por ser feito por seres humanos, e nem se torna humano porque a voz humana nele ressoa, mas apenas quando se tornou objeto do discurso. [...]. Humanizamos o que ocorre no mundo e em nós mesmos apenas ao falar disso, e no curso da fala aprendemos a ser humanos.

Em relação ao imperdoável, Hunt adverte que não é a intensidade da violência que determina a vingança e o fim da pluralidade, mas o caráter determinístico que move a ação (HUNT, 2015, p. 285). Na verdade, os crimes contra a humanidade, como os cometidos pelo nazismo, são, segundo Arendt, imperdoáveis. Não são, por exemplo, concebidos pelo indivíduo, que, como Eichmann, figura emblemática, seguia a lei: "Ele atuou como cidadão cumpridor da lei." (HUNT, 2015, p. 286). O nazismo rompeu com a tradição, mostrando o absurdo da ideologia totalitária, diferindo de todos os crimes de guerra, "não só em grau de seriedade, mas em essência" (ARENDT, 2011, p. 290).

Essa realidade é exposta por Arendt nas passagens (2011, p. 291):

Foi quando o regime nazista declarou que o povo alemão não só não estava disposto a ter judeus na Alemanha, mas desejava fazer todo o povo judeu desaparecer da face da Terra que passou a existir o novo crime, o crime contra a humanidade - no sentido de "crime contra o status humano", ou contra a própria natureza da humanidade. 
E:

A expulsão e genocídio, embora sejam ambos crimes internacionais, devem ser distinguidos; o primeiro é crime contra as nações irmãs, enquanto o último é um ataque à diversidade humana enquanto tal, isto é, a uma característica do "status humano" sem a qual a simples palavra "humanidade" perde o sentido.

Essas palavras não deixam dúvidas da seriedade do tratamento perverso perpetrado contra a natureza humana. Se a expulsão constitui crime contra os povos em geral, o segundo é contra a própria natureza humana. Como já tivemos a oportunidade de dizer, o trato entre os homens, tanto dos algozes como das vítimas, preenchiam o quesito de "desumano".

Para a autora, a postura de Eichmann em vista do determinismo das leis destruiu a espontaneidade e o pluralismo (HUNT, 2015, p. 287). Com efeito, a destruição dessas formas de ação implica na destruição da própria essência do humano. Assim, o crime não é contra unicamente os judeus, mas contra a humanidade. Um trecho de As origens do totalitarismo (2012c) apresenta essa posição da autora em relação a esses crimes imperdoáveis, imputados aos regimes totalitários:

Até agora, a crença totalitária de que tudo é possível parece ter provado apenas que tudo pode ser destruído. Não obstante, em seu afã de provar que tudo é possível, os regimes totalitários descobriram, sem o saber, que existem crimes que os homens não podem punir nem perdoar. Ao tornar-se possível, o impossível passou a ser o mal absoluto, impunível e imperdoável, que já não podia ser compreendido nem explicado pelos motivos malignos do egoísmo, da ganância, da cobiça, do ressentimento, do desejo do poder e da covardia; e que, portanto, a ira não podia vingar, o amor não podia suportar, a amizade não podia perdoar. Do mesmo modo como as vítimas nas fábricas da morte ou nos poços do esquecimento já não são "humanas" aos olhos de seus carrascos, também essa novíssima espécie de criminosos situa-se além dos limites da própria solidariedade do pecado humano. (ARENDT, 2012c, p.510; ARENDT, 1951, p. 459apud HUNT, 2015, p. 287 nota 09)

Para a autora, no início do regime nazista, o ressentimento servia para explicar o antissemitismo, porém, com o advento das 'fábricas da morte', perdeu o sentido. Nas palavras de Hunt (2015, p. 288): "Com o advento das fábricas da morte, descobrimos que os motivos humanos do egoísmo, o desejo de poder e o ressentimento não são mais capazes de dar sentido ao mundo."

Para Arendt, essa emoção, reconhecida nas relações entre os homens, foi destruída com o totalitarismo (HUNT, 2015, p. 288). Como essa destruição acontece, podemos observar em duas práticas utilizadas pelos nazistas: SA (Sturmabteilung) e nas da SS (Schutztaffel). A SA agia meramente movida pelo ódio irracional para a aniquilação de um povo, não estando, segundo a autora, envolvida qualquer emoção humana. Na verdade, Arendt observa um resquício de sentimento humano no ressentimento alimentado pelos torturadores, e que, de alguma forma, contribui para diferenciar uma réstia do que era humano. Essa tortura sádica, por sua vez, distinguia-se de outra, racional, levada a cabo pela SS. Nas palavras de Arendt (ARENDT, 2012c, p. 505):

Atrás da bestialidade cega da SA, frequentemente havia um profundo ódio e ressentimento contra os que eram social, intelectual ou fisicamente melhores que eles, e 
que estavam agora à mercê, como numa realização dos seus mais loucos sonhos. Esse ressentimento, que nunca chegou a desaparecer inteiramente dos campos, parece-nos o derradeiro vestígio de um sentimento humanamente compreensível.

E, completa:

O verdadeiro horror, porém, começou quando a SS tomou a seu cargo a administração dos campos. A antiga bestialidade espontânea cedeu lugar à destruição absolutamente fria e sistemática de corpos humanos, calculada para aniquilar a dignidade humana. Os campos já não eram mais parques de diversões de animais sob forma humana, isto é, de homens que realmente deveriam estar no hospício ou na prisão; agora eram “campos de treinamento", onde homens perfeitamente normais eram treinados para tornarem-se perfeitos serem membros da SS.

Para finalizar, podemos dizer que o ressentimento corresponde à emoção entre sujeitos, e não entre sujeito e objeto. O que significa isso? Significa que a fábrica da morte destruía essa emoção, uma vez que tratava os indivíduos como peças, negando inteiramente a humanidade. Diante da lógica implacável do cálculo predominava a frieza, o respeito à exigência da ordem totalitária, o que correspondia ao que Arendt em Eichmann em Jerusalém (2011) chamou de "banalidade do mal".

Essa realidade ultrapassa a compreensão do mal na sociedade, pois acaba com o que se entende da natureza humana, tão estudada pelos pensadores ${ }^{16}$. Podia-se compreender o racismo, o sadismo, a inveja, a ganância, e outros estados de ânimo, partindo de emoções originárias inibidas em sua finalidade. Essas emoções, como vimos na exposição do ressentimento moral, contribuem para a justiça, garantindo, dessa forma, o espaço público. Por outro lado, o ressentimento social, conforme a noção, atribuída a Nietzsche, de ressentimento ontológico, pode ser destrutivo, como notamos nas ideologias totalitárias.

\footnotetext{
${ }_{16}$ Parece correto afirmar que os crimes do nazismo acabam com a natureza e com a condição humana, ou seja, no sentido de ser contrário à espécie e contrário à experiência da liberdade do homem, da pluralidade (SCHIO, 2010, p. 162).
} 


\section{Referências}

ANSELL-PERSON, K. Nietzsche como pensador político: uma introdução. Tradução de Mauro Gama e Claudia Martinelli Gama. Rio de Janeiro: Jorge Zahar Editor, 1997.

ARENDT, H. A condição humana. Tradução de Roberto Raposo. Rio de Janeiro: Forense Universitária, 2012a.

ARENDT, H. Sobre a Revolução. Tradução de I. Morais. Lisboa: Relógio d'Água, 2001.

ARENDT, H. A tradição do pensamento político. In:_A promessa da política. Tradução de Pedro Jorgensen Jr. Rio de Janeiro: DIFEL, 2012b.

ARENDT, H. A crise da república. Tradução de José Volkmann. São Paulo: Perspectiva, 2010. ARENDT, H.Sobre a violência. Tradução de André Duarte. Rio de Janeiro: Civilização Brasileira, 2009b.

ARENDT, H. Responsabilidade e julgamento. Tradução de Rosaura Eichenberg. São Paulo: Companhia das Letras, 2004.

ARENDT, H.Origens do Totalitarismo. Tradução de Roberto Raposo. São Paulo: Companhia das Letras, 2012c.

ARENDT, H. The Origins of Totalitarianism. New York: Harcourt, 1951.

ARENDT, H. Entre o passado e o futuro, Tradução de Mauro W. Barbosa. São Paulo: Perspectiva, 2009a.

ARENDT, H.Eichmann in Jerusalem: A Reportonthe Banality of Evil. New York: Penguin Classics, 2006.

ARENDT, H. Eichmann em Jerusalém: um relato sobre a banalidade do mal. Tradução de José R. Siqueira. São Paulo: Companhia das Letras, 2011.

ARENDT, H. Homens em tempos sombrios. Tradução de Denise Bottman. Companhai das Letras, 1987.

BRUSOTTI, Marco. Ressentimento e Vontade de Nada. Cadernos Nietzsche, $\mathrm{n}^{\circ}$ 8, p. 3-34, 2000. CANOVAN, M. Hannah Arendt: A Reinterpretation of Her Political Thought. New York: Cambridge University Press, 1995.

DELEUZE, G. Nietzsche e a filosofia. Tradução de Edmundo Fernandes Dias e Ruth Joffily dias. Rio de Janeiro: Editora Rio, 1976.

DUARTE, A. Poder e violência no pensamento político de Hannah Arendt: uma reconsideração (ensaio crítico). In: ARENDT, H. Sobre a violência, 2009b, p. 131-167.

FASSIN, Didier. On Resentment and Ressentiment: The Politicsand Ethics of Moral Emotions. Current Anthropology, Vol. 54, nº 03, p. 249-267, 2013.

http://www.jstor.org/stable/10.1086/670390

Acessado 07/06/2019.

GIACOIA, Oswaldo. Nietzsche: o humano como memória e como promessa. Petrópolis: Editora Vozes, 2013.

GIACOIA, Oswaldo. Nietzsche como psicólogo. São Leopoldo: Editora UNISINOS, 2001.

HAYDEN, P. (ed.) Hannah Arendt: Key Concepts. Durham: Acumen, 2014.

HONIG, B. Declarationsof Independence: Arendt and Derrida on the Problemof Founsing a Republic. The American Political Science Review. Vol. 85, No. 1, p. 97-113, 1991.

HONIG, B. Political Theoryandthe Displacement of Politics (Contestations). Ithaca e London: Cornell University, 1993.

HUNT, Grayson. Arendt on Resentment: Articulating Intersubjetivity. The Journal of Speculative Philosophy, vol. 29, nº 03, p. 283-290, 2015. 
http://muse.jhu.edu/article/588863

JACOBITTI, Suzanne D. The Public, The Private, The Moral: Hannah Arendt and Political Morality. International Political Science Review/Revue Internationale de Science Politique. Vol. 12, No 4, p. 288-293, 1991.

KRISTEVA, J. O gênio feminino: a vida, a loucura, as palavras. Tomo I: Hannah Arendt. Tradução de Eduardo Francisco Alves. Rio de Janeiro: Rocco, 2002.

LA CAZE, M. Promising and forgiveness. In: HAYDEN, P. (ed.) Hannah Arendt: Key Concepts. Durham: Acumen, 2014, p. 209-221.

MACLACHLAN, Alice. Unreasonable Resentments. Journalof Social Philosophy, Vol. 41, N. 4, p. 422-441, 2010.

MARIN, Solange R. \& QUINTANA, André M. O Sentido Subjetivo: O Ressentimento como Circunstância de Justiça em Adam Smith. Filosofía de la Economía, Vol. 04, p. 87-103, 2015. http://ppct.caicyt.gov.ar/index.php/filoecon/article/view/4518

Acessado em 13/07/2019 às 15:15.

NIETZSCHE, F. Genealogia da moral. Tradução de Paulo César de Souza. São Paulo: Companhia das Letras, 2004.

PASCHOAL, A. E. As formas do ressentimento na Filosofia de Nietzsche. Philósophos, Vol. 13, $\mathrm{N}^{\circ}$ 1: p. 11-33, 2008.

SCHELER, Max. El resentimientoenla moral. Traducción por José Gaos. Madrid: Revista de Occidente, 1927.

SCHIO, Sonia M. A Ética da Responsabilidade em Arendt e Jonas. Dissertatio, Vol. 32, p. 157 $174,2010$.

SCHIO, Sonia M. O estado teorizado por Hobbes segundo a perspectiva de Hannah Arendt. Revista Reflexões, $\mathrm{n}^{\circ}$ 10, p. 180-195, 2017.

http://revistareflexoes.com.br/wp-content/uploads/2017/07/12.1.1-Sonia-UFEpel-181-a-195.pdf Acessado em 26/07/2019 às 15 h50.

SCHWARZE, M. \& SCOTT, J. T. Spontaneous Disorder in Adam Smith's Theory of Moral Sentiments: Resentment, Injustice, and the Appeal to Providence. The Journal of Politics, Vol. 77, no. 2, p. 463-476, 2015. https://www.jstor.org/stable/10.1086/679750.

SMITH, Adam. Teoria dos sentimentos morais. Tradução de Lya Luft. São Paulo: Martins Fontes, 1999.

URE, Michael. Resentment/Ressentment. In: Constellations: na InternationalJournal of Criticaland Democratic Theory, vol. 22, n 04, p. 599-613, 2015.

Autor(a) para correspondência: Ricardo Gião Bortolotti, Av. Dom Antonio, 2100, Parque Universitário, 19806-900, Assis - SP, Brasil. bortho@uol.com.br 